\title{
A Study of Intentional Ambiguity from the Perspective of Pragmatics
}

\author{
Ruihong Huang \\ Teaching Center, Zhejiang Open University, Hangzhou, China \\ Email:870534247@qq.com
}

How to cite this paper: Huang, R.H. (2020) A Study of Intentional Ambiguity from the Perspective of Pragmatics. Open Access Library Journal, 7: e6182. https://doi.org/10.4236/oalib.1106182

Received: February 22, 2020

Accepted: March 15, 2020

Published: March 18, 2020

Copyright ( 2020 by author(s) and Open Access Library Inc.

This work is licensed under the Creative Commons Attribution International License (CC BY 4.0).

http://creativecommons.org/licenses/by/4.0/

\section{(c) (i) Open Access}

\begin{abstract}
Intentional ambiguity refers to the linguistic phenomenon that the addresser consciously uses some indirect or ambiguous words to express illocutionary forces to the addressee in the specific context. By analyzing the intentional ambiguity from the perspective of pragmatic definition, pragmatic connotation, pragmatic theory and pragmatic value, it shows that the dynamic study of intentional ambiguity based on pragmatics is conducive to explain the phenomenon of intentional ambiguity in communication. As long as it is used skillfully in the specific context, intentional ambiguity can be an effective communicative strategy to help the communicators achieve their communication intention.
\end{abstract}

\section{Subject Areas}

Linguistics

\section{Keywords}

Intentional Ambiguity, Pragmatics, Pragmatic Connotation, Pragmatic Value

\section{Introduction}

As a common linguistic phenomenon in conversational communication, ambiguity has always been concerned by linguists. The traditional view holds that ambiguity belongs to misuse in language communication, which will have a negative impact on the communication process and hinder the normal communication activities. In recent years, with the development of linguistic research and the deepening of the study of ambiguity, linguists have found that ambiguity is not only a misuse or a language disorder. As long as it is used flexibly and effectively in a specific context, ambiguity can become a communicative strategy 
to achieve communication intention. This kind of ambiguity phenomenon consciously used in the process of language communication is intentional ambiguity, which is also defined as a communicative strategy.

Because of the polysemy of language itself [1], intentional ambiguity is widely used in conversational communication. However, scholars' researches on intentional ambiguity are mostly static at the linguistic level. Dynamic research is only sporadic, and few scholars have explored the connotation and function of intentional ambiguity from the perspective of pragmatics. In view of this, this study will use the perspective of dynamic pragmatics, based on Grice's Cooperation Principle, Leech's Politeness Principle, Brown \& Levinson's Face-saving Theory, to construct a research framework for intentional ambiguity, including pragmatic definition, pragmatic connotation, pragmatic theory and pragmatic value.

\section{Pragmatic Definition of Intentional Ambiguity: Illocutionary Forces}

Ambiguity is a linguistic phenomenon in which a word or utterance produces two or more interpretations in the process of language use [2]. According to the communicative effect and communicative language view, ambiguity can be divided into two categories: unintentional ambiguity and intentional ambiguity. Unintentional ambiguity is a misunderstanding or language disorder that both sides of communication unconsciously or naturally show in the process of communication, which shows the contradictory characteristics of language structure itself. However, intentional ambiguity is different. As a kind of communicative strategy, intentional ambiguity means that the communicator intentionally distorts the other party's speech intention in order to achieve a certain communicative purpose and attain a specific communicative effect. Intentional ambiguity from the perspective of pragmatics refers to the linguistic phenomenon that the speaker consciously uses some vague, indirect or ambiguous words to express multiple illocutionary forces to the addressee in the specific context [3]. In order to achieve their communicative intention, the communicators use the communicative language skillfully and flexibly, which results in the illocutionary force in communicative discourse and the intentional ambiguity.

\section{Example 1}

Professor Robert knocked on the desk and shouted: "Class, order!"

The whole class yelled: "Beer!"

The context of this dialogue is that in the classroom, the students are very noisy, so the professor knocks on the platform and loudly asks the students to be quiet, but why don't the students stop the noise and answer it with the "beer" of the inappropriate questions? The reason is that the word "order" can be interpreted as "keep order" or "quiet", or "order food" when ordering food and drink in a hotel or restaurant. Students use intentional ambiguity in one voice "beer!" to playfully answer the professor's serious "order", adjusting the unhappiness between teachers and students in class and avoiding conflicts. 


\section{Pragmatic Connotation of Intentional Ambiguity: Specific Context}

The English language itself has the characteristics of large vocabulary, many homonyms, flexible grammar and so on, which makes it possible for people to have ambiguity in the process of using the English language for communication. According to these characteristics of English language, communicators use intentional ambiguities flexibly and cleverly to produce humorous communication effects. In some specific contexts, there may be two or more different explanations for the speaker's uncertain speech or the lack of information in the speech. The addressee can use this phenomenon to choose different interpretations of the real speech that the speaker wants to express in several interpretations, and realize his communicative purpose by deliberately misinterpreting the speaker's speech. In the following paragraphs, the pragmatic connotation of intentional ambiguity will be analyzed from the phonetic level, lexical level and syntactic level.

\subsection{Intentional Ambiguity at Phonetic Level}

Intentional ambiguity at the phonetic level is the result of different understandings of the addressee due to phonetic ambiguity in a specific context. It mainly uses homophones or homonyms of English words to achieve the purpose of communication. If two English words with different meanings have the same pronunciation, whether they have the same spelling or not, it may lead to ambiguity in communication.

\section{Example 2}

More sun and air for your son and heir.

The short advertisement is designed by the travel agency to attract tourists. It means that parents should take your children to the seaside, where there is plenty of sunshine and fresh air. Intentional ambiguity results from homonyms "sun/son" and "air /heir". This advertisement has a strong persuasion and attraction by skillfully using the communicative strategy of intentional ambiguity. Just imagine: our beach has bright sunshine and fresh air, which will be good for the physical and mental health of your son, your heir. How can such words not make tourists yearn? The intentional ambiguity in the phonetic level of advertising language is widely used. The advertising language with ambiguity makes the advertisement have the effect of one true one false, one bright one dark. It makes people imagine and achieve the interesting communicative purpose of advertisement.

\subsection{Intentional Ambiguity at Lexical Level}

Intentional ambiguity at the lexical level is mainly caused by polysemy, different parts of speech or different meanings expressed in different contexts [4]. The polysemy of a word is very common in the English language. Apart from some special professional words and terms, many English words have more than two 
or even as many as a dozen interpretations. However, in a specific context, generally speaking, only one interpretation will be retained, and other interpretations will be filtered out, but there are also some special situations.

\section{Example 3}

Money doesn't grow on tree. But it blossoms at our branches. ------ Lloyd Bank

Lloyd Bank makes full use of the communicative strategy of intentional ambiguity to achieve its own communication purpose. Here, "branch" has two meanings. One is the surface interpretation, that is, the literal meaning of "branch", a part of a tree, while the deep interpretation refers to each branch of Lloyd Bank. The real meaning of the sentence is that as long as customers keep their money in the Lloyd Bank, their deposits will continue to grow.

\subsection{Intentional Ambiguity at Syntactic Level}

For the same sentence, different people may analyze and divide the syntactic structure differently, which leads to different meanings and different understandings. In a specific context, when different people have different interpretations of the same sentence, there will be ambiguity [5], and if the misinterpretation is intentional, there will be intentional ambiguity at the syntactic level.

\section{Example 4}

A: The police is looking for a man with one eye.

B: Why don't they use two?

This kind of dialogue humor is caused by the different understanding of syntactic structure. A's words say the fact that "the police is looking for a person with only one eye". Here "with one eye" is used to modify the noun "a man" in front of it. But B deliberately misinterprets "with one eye" to modify the verb phrase "is looking for", which can be misinterpreted as "the police is looking for a man using one eye", and then puts forward the following question, "why don't they use two eyes?" Here, different understandings of syntactic structures are used to create intentional ambiguity, which achieves a humorous communicative effect.

\section{Pragmatic Theory of Intentional Ambiguity: Deep Meaning}

It can be seen from the pragmatic connotation of intentional ambiguity, especially in a specific context, intentional ambiguity often produces unexpected humorous pragmatic effects, which will be explored from the pragmatic theories such as Grice's Cooperative Principle, Leech's Politeness Principle, Brown \& Levinson's Face Theory.

\subsection{Intentional Ambiguity Embodied in Cooperative Principle}

Grice, a famous American philosopher, believes that in order to achieve a specific communicative purpose, there will be a tacit understanding between the 
two parties to abide by the cooperative principle, which is embodied in the following four sub-maxims [6]:

1) The Maxim of Quality: Try to make your contribution one that is true. Do not say what you believe to be false. Do not say that for which you lack adequate evidence.

2) The Maxim of Quantity: Make your contribution as informative as is required (for the current purposes of the exchange). Do not make your contribution more informative than is required.

3) The Maxim of Relevance: Be relevant.

4) The Maxim of Manner: Be perspicuous. Avoid obscurity of expression. Avoid ambiguity. Be brief. Be orderly.

It has been proved that both sides of communication are creative and flexible in using communicative language. In the process of communication, people will not only consciously follow these guidelines, but also deliberately violate some of them to achieve their communicative intention, intentional ambiguity is a typical one. Obviously, intentional ambiguity violates Grice's manner maxim of "avoid ambiguity". However, although intentional ambiguity seems to violate the manner maxim in the literal sense, it still abides by the cooperative principle in the deep sense. In fact, violation of the maxims can also be understood as a special manifestation of abiding by the cooperative principle. The reason is that when the communicator uses intentional ambiguity in the process of communication, his words can be understood as two different levels: literal meaning and deep meaning. It is obvious that the communicator violates the cooperative principle, but in terms of the deep meaning, the communicator still abides by the cooperative principle, because the communicator provides the exact discourse information, and the key is how the addressee understands it. For example:

\section{Example 5}

She cannot bear children.

Interpretation 1: She can't have children (because she has infertility).

Interpretation 2: She can't stand the noise of the children.

The verb "bear" has two completely different meanings. In Interpretation 1, it can be understood as "have or give birth", but in Interpretation 2, it means "stand or deal with". The context of the dialogue is that a couple has not had children for many years. When a friend asks them why they have no children, the husband uses intentional ambiguity and cleverly uses the above sentence to answer. Generally speaking, Interpretation 1 is the surface meaning representing the real situation, and Interpretation 2 is the deep meaning that the speaker wants the addressee to understand his words. In fact, the husband's response not only abides by the cooperative principle, but also protects his privacy, so as to get rid of the embarrassing situation. Although the speaker doesn't follow the maxim of manner, he effectively follows the maxim of quality.

\subsection{Intentional Ambiguity Embodied in Politeness Principle}

Politeness refers to the attitude of one side towards the other in the process of 
communication. According to the famous linguist Leech, there are six maxims of politeness principle, namely, tact maxim, generosity maxim, approbation maxim, modesty maxim, agreement maxim, and sympathy maxim [7]. The most fundamental and important of the six maxims is tact maxim. In fact, the polite use of language by both parties indicates the tactical use of language. Essentially, politeness principle hopes that the two sides of communication can reduce their differences as much as possible in the process of communication, try not to let the other side feel embarrassed, and do not use words to belittle the other side. For the relationship between politeness principle and cooperative principle, Leech believes that politeness principle can effectively protect the good relationship between the two sides of communication, minimize impoliteness, and play a positive role in the process of communication. The cooperative principle is to explain the relationship between the literal meaning and the deep meaning of the communication, at the same time, it explains the causes of conversational implicature. Therefore, politeness principle is able to "rescue" cooperative principle. Politeness principle and cooperative principle complement each other, which can explain why the two parties deliberately violate cooperative principle in the process of communication.

\section{Example 6}

I have never found Jack to be incompetent.

Interpretation 1: I have never found that Jack is incompetent. (He is very capable).

Interpretation 2: I have never found that Jack's ability is not good. (But I am skeptical of his ability, because there are still many things to be improved in his work, "have never found" does not mean that he is capable).

The context of the dialogue is that a professor is asked to comment on Jack's ability. The professor knows Jack very well and knows that Jack is incompetent. However, for the sake of politeness principle, it is inconvenient for the professor to directly say that Jack is incompetent; at the same time, from the quality maxim of cooperative principle, he can't cheat others by lying casually. In such a dilemma, the professor cleverly uses intentional ambiguity as a communicative strategy to say the above words that can make the other party guess. Interpretation 2 is the deep meaning indicates that the professor does not approve of Jack's ability.

\subsection{Intentional Ambiguity Embodied in Face-Saving Theory}

After Leech, famous linguists Brown and Levinson make a further in-depth study and discussion on politeness principle. They define politeness as politeness is a variety of rational behaviors adopted by "typical people" to meet their own face needs [8]. Their politeness theory is called "face-saving theory", that is to say, in the process of communication, they try to use some language strategies to save face for both sides.

According to Brown and Levinson, in the process of communication, a lot of 
words in the deep sense will threaten the face of both sides. Therefore, in communication, we should try to consider the needs of the other party's face. By following the politeness principle, we can make face for ourselves and the other party at the same time, which will not lead to very embarrassing situation.

\section{Example 7}

Stranger: Boy, will you direct me to the bank?

Boy: I will ask for a dollar.

Stranger: A dollar! That's a high pay, isn't it?

Boy: Yes, but I know bank directors always get high pay.

The context of the above dialogue is that a stranger asks the little boy to take him to the bank. The intentional ambiguity arises in the "bank director", which means "bank manager" on the surface, while the deep meaning can be understood as "guide". The little boy cleverly uses intentional ambiguity to find a good excuse for his asking price of one dollar, and doesn't directly contradict the strangers, so he is very tactful to achieve the purpose of saving both sides' faces, letting the stranger accept his own requirements in humor, and successfully realizing his communicative intention.

\section{Pragmatic Value of Intentional Ambiguity: Communicative Effect}

Intentional ambiguity refers to the conscious choice and adjustment of utterance strategies according to context and communicative intention. The flexible use of intentional ambiguity shows that the communicators have excellent speech ability and high speech wit. Therefore, intentional ambiguity is widely used in people's communication activities to enhance mutual communication. As an effective communicative strategy, intentional ambiguity can produce pragmatic effects beyond surface language, making the communication language novel and peculiar [9]. The communicators use intentional ambiguity skillfully to achieve some special pragmatic purposes, which fully demonstrates the pragmatic value of intentional ambiguity.

\subsection{Intentional Ambiguity Can Effectively Reverse Unfavorable Situation}

Creative use of intentional ambiguity can achieve the communicative effect of pun, a clever use of a word with two meanings, which plays a positive role in getting rid of the embarrassment and predicament in the process of communication.

\section{Example 8}

"This is a white hotel," he said. I looked around. "It isn't white, such a color needs much cleaning," I said. "But I don't think I mind."

In this dialogue, the owner of the hotel intends to say that the hotel is only for whites. The word "white" can be understood as both white people and white color. Therefore, as an African-American, "I" deliberately understand as "the 
hotel's color is white", and then say that to be white, it needs to be cleaned, implying that the hotel is not clean enough, and finally say, "but I don't care.". In this dialogue, "I" make use of intentional ambiguity to make the communication process beneficial to myself, and effectively avoid direct confrontation between the two sides through the transfer of topics, thus reversing unfavorable situation and getting rid of the embarrassing situation.

\subsection{Intentional Ambiguity Can Vividly Portray Character Image}

In order to achieve the unexpected communicative effect, the communicators can make the characters vivid by using intentional ambiguity skillfully, which helps to push the story to the climax.

\section{Example 9}

A: I understand you had an argument with your wife. How did it end up?

$\mathrm{B}$ : Oh, she came crawling to me on her hands and knees.

A: Is that so? What did she say?

B: She said, "Crawl out from under the bed and fight like a man."

In this humor, a friend asks about the result of the quarrel between husband and wife. At the beginning of the dialogue, the husband uses intentional ambiguity to say that his wife crawls towards him on her hands and knees, which makes people feel that his wife is admitting her mistake and the husband is in a dominant position in the quarrel. The last sentence reveals the real situation. It turns out that the husband is beaten under the bed by his wife and is afraid to climb out. Such a big turning point happens with the dramatic effect, a husband with a strict wife is vividly presented, which is impressive.

\subsection{Intentional Ambiguity Can Actively Produce Communicative Effects}

In a specific context, the communicators can use intentional ambiguity to create humorous, ironic, satirical and other special communicative effects.

\section{Example 10}

A asks his friend B about the reason for his visit to Los Angeles.

A: What brought you from New York to Los Angles?

B: A plane.

Friend A asks friend B, "What brought you to Los Angeles?", which means, "Why did you come to Los Angeles?". In order to play a joke with friend A, friend $\mathrm{B}$ uses intentional ambiguity to understand the literal meaning, thus producing humorous effect and creating a relaxed and happy atmosphere.

\section{Example 11}

A man was in court charged with parking his car in a restricted area. The judge asked him if he had anything to say in his defense.

"They shouldn't put up such misleading notices," said the man. "It said, FINE FOR PARKING HERE."

In the above story, the main reason for intentional ambiguity is that the Eng- 
lish word "fine" can be interpreted as both "forfeit" and "good". The meaning of the sign is "there is a forfeit for parking here", and the man who is summoned by the court for random parking deliberately understands the sign as "parking here is very good". Through this defense, he tries to avoid being punished by the judge. Intentional ambiguity here can create a special communication effect.

\section{Conclusion}

This study makes a dynamic research of intentional ambiguity by using pragmatic theory, focusing on the communicative purpose and communicative intention of the addresser and the addressee. And a comprehensive study of intentional ambiguity from the aspects of pragmatic definition, pragmatic connotation, pragmatic theory and pragmatic value is helpful to deepen the understanding of intentional ambiguity. This paper finds that intentional ambiguity is caused by the illocutionary force contained in the communicative discourse; as long as it is used skillfully and flexibly in a specific context, intentional ambiguity can become an effective communicative strategy to help the communicators achieve their own communicative intention and communicative purpose; and the pragmatic value of intentional ambiguity fully shows that intentional ambiguity has a good communicative effect. Of course, ambiguity in English is a complicated subject. From the perspective of pragmatics, this paper discusses intentional ambiguity as communication strategies in order to have a more comprehensive and objective understanding of intentional ambiguity.

\section{Acknowledgements}

My thanks to the anonymous reviewers for reading and commenting on the early drafts of this article.

\section{Conflicts of Interest}

The author declares no conflicts of interest regarding the publication of this paper.

\section{Funding}

The project is supported by the Program for Research on the Paradigm Establishment of Curriculum Construction in Open University (Grant No. jg20191071), the Second Batch of Teaching Reform Research Projects in "the 13th Five-Year Plan" of Higher Education in Zhejiang Province, Innovation Research Team of English Teaching Paradigm of Zhejiang Open University in 2019, Huang Ruihong Excellent Teacher Studio of Applied English.

\section{References}

[1] Wang, Y. (2019) Researches on the Psychological Representation of Ambiguous Words. Journal of Heilongjiang College of Education, 3, 117-119.

[2] Wu, S. (2000) Pragmatic Analysis of Ambiguity. Journal of Beijing International 
Studies University, 6, 6-10.

[3] Thomas, J.A. (1995) Meaning in Interaction: An Introduction to Pragmatics. Longman, London, 142.

[4] Wang, J. (2009) Pragmatic Value and Translation Method of Lexical Ambiguity in Advertising English. Journal of North China University of Science and Technology (Social Science Edition), 1, 112-115.

[5] Li, X.Q. (2008) A Cognitive Analysis on English Structural Ambiguity. Journal of Jishou University (Social Science Edition), 11, 136.

[6] Grice, H.P. (1975) Syntax and Semantics 3: Speech Acts. Academic Press, New York, 61-63.

[7] Leech, G. (1983) Principles of Pragmatics. Longman, London, 132-135.

[8] Brown, P. and Levinson. (1987) Politeness: Some Universals of Language Usage. Cambridge University Press, Cambridge, 69-73. https://doi.org/10.1017/CBO9780511813085

[9] Li, J.W. (2016) Study of Positive Impact of Slogan Deliberate Ambiguity. Journal of Hebei Jiaotong Vocational and Technical College, 9, 77-80. 